WellBeing International

WBI Studies Repository

$6-2013$

\title{
Site Fidelity and Homing Behaviour in Intertidal Fishes
}

\author{
Gemma E. White \\ Macquarie University \\ Culum Brown \\ Macquarie University
}

Follow this and additional works at: https://www.wellbeingintlstudiesrepository.org/acwp_asie

Part of the Animal Studies Commons, Comparative Psychology Commons, and the Other Animal Sciences Commons

\section{Recommended Citation}

White, G. E., \& Brown, C. (2013). Site fidelity and homing behaviour in intertidal fishes. Marine biology, 160(6), 1365-1372.

This material is brought to you for free and open access by WellBeing International. It has been accepted for inclusion by an authorized administrator of the WBI Studies Repository. For more information, please contact wbisr-info@wellbeingintl.org.

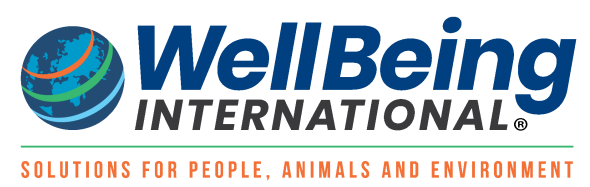




\title{
Site fidelity and homing behaviour in intertidal fishes
}

\author{
Gemma E. White and Culum Brown \\ Macquarie University
}

\begin{abstract}
The theory of ecological cognition poses that the brains and behaviour of animals are shaped by the environmental challenges they face in their everyday lives. Site fidelity and homing ability was tested for five species of intertidal rock pool fish by tagging and displacing them to new rock pools at various distances from their 'home' rock pools. Three of the species were rock pool specialists whilst the remaining two spend a small proportion of their life in rock pools during early ontogeny. The three specialists showed strong site fidelity with $>50 \%$ of individuals found in the same pool 42 days after tagging. In contrast, the non-specialist species showed low fidelity and poor homing abilities. Homing success in the rock pool specialists remained relatively stable as displacement distance increased. The effect of body size on homing ability was species dependent, with only one species showing a significantly greater tendency to home with increasing size.
\end{abstract}

\section{Introduction}

Homing behaviour has been generally defined as the ability of an animal to return to a spatially restricted location that it previously occupied following displacement to an unfamiliar site (Williams 1957; Gerking 1959; Papi 1992). Homing behaviour has been documented in a wide range of vertebrate species (Papi 1992; Healy 1998; Gibson 1999) and is expected to convey significant fitness advantages. One of the key benefits of homing is that it ensures an animal returns to a familiar location. Survival is often reduced in unfamiliar locations, even when these locations are apparently similar to originally occupied habitats, because displaced individuals often lack detailed crucial information about unfamiliar sites (Piper 2011). For example, the identities of neighbours, locations where predators hide or location of food sources may be unknown. The high mortality rates recorded for displaced animals (Reinert and Rupert 1999; Letty et al. 2003) and the fact that animals show enhanced escape responses in familiar contexts (Brown 2001) provide further support that site familiarity is important for survival. Moreover, animals that are familiar with their territory invest more to defend it because they place a higher value on the resource (residency effect; Maynard Smith and Parker 1976).

Homing is likely to be particularly important in extreme environments, where conditions fluctuate greatly over space and time. In intertidal fish, for example, survival may be influenced by an individual's ability to return to its home rock pool after high tide feeding excursions and thereby avoid being stranded in unsuitable areas at low tide (Williams 1957). Consequently, homing is expected to be a key feature of intertidal fish species and has been observed in numerous families including Blennidae (Stephens et al. 1970), Cottidae (Khoo 1974; Yoshiyama et al. 1992) and Gobiidae (Berti et al. 1994). A number of studies 
have examined the capacity of fish to 'home' by displacing individuals at various distances from the area in which they were originally captured (Green 1971; Carlson and Haight 1972: Kolm et al. 2005). When Beebe (1931) removed frillfin gobies (Bathygobius soporator) from one rock pool and displaced them into another, they generally returned to the original pool of capture. In general, homing success decreases as displacement distance increases. Opaleyes (Girella nigricans), for example, return home after being displaced up to $54 \mathrm{~m}$; however, the percentage of returning fish decreases as displacement distance increases (Valle 1989).

Homing success necessitates the development and evolution of cognitive abilities that enables individuals to remember cues and use them to aid in orientation when returning to key resources. The ecological cognition hypothesis suggests that cognitive abilities and behaviours of individuals are largely shaped by environments in which they live and associated challenges they must overcome during their lives (Healy and Braithwaite 2000). For example, populations of fish from high and low predation regimes differ in their ability to solve a radial maze (Brown and Braithwaite 2004). In the present context, intertidal fishes need to remember the locations of safe tide pools so that they can return to them, which requires spatial learning and memory skills. Comparative studies have shown that in birds (Balda and Kamil 1992), mammals (Gaulin and FitzGerald 1986) and fish (Costa et al. 2011), there is a positive relationship between telencephalon size, spatial learning abilities and the expected demand for spatial learning based on an analysis of their life history strategies. Despite the variety of work examining homing responses in intertidal fishes, most homing studies have focussed on fish that spend their entire lives within the intertidal zone and there have been no comparisons of how life history strategy affects homing ability in these species.

Here, we compared the homing behaviours of five abundant species of inter-tidal fish found on temperate rocky shores in the Sydney region of Australia. These species comprised a mixture of residents: cocos frillgoby (Bathygobius cocosensis), eastern jumping blenny (Lepidoblennius haplodactylus), and ringscale triplefin (Enneapterygius atrogulare), and secondary residents: fortescue (Centropogon australis), and stripey (Microcanthus strigatus). These two groups show extensive behavioural, habitat and life history differences. Most importantly from an ecological cognition perspective, resident fish remain within the intertidal zone for their entire lives, whereas secondary residents only remain within the intertidal zone during the juvenile stage of development after which an ontogenetic shift to off-shore habitats occurs to complete the life history. Using these two groups, we addressed two primary questions: (1) do residents and secondary residents vary in the degree of site fidelity? (2) do resident species differ from secondary resident species in homing success when displaced to increasing distances from their home pools?

According to the ecological cognition hypothesis, we predict that natural selection would favour evolution of enhanced spatial memories in rock pool resident species. By comparison, the level of selective pressure is expected to be significantly less in secondary residents. Thus, we expected that resident species would show high site fidelity and enhanced homing abilities. We further predicted that homing success in resident species would increase with age, as larger fish would have obtained a greater familiarity with the surrounding environment. In contrast, we predicted that homing success of secondary residents would decrease with age as these fish prepare to leave the intertidal zone.

\section{Methodology}

\section{Study animals}

The five species of inter-tidal fish observed in this study displayed two very different life history strategies and showed extensive morphological, behavioural and habitat differences. Residents, which spend their entire life (juvenile to adult) within the intertidal zone, are morphologically highly adapted for life in this 
habitat. They have small and slender bodies, eyes placed high on head, cryptic colouring (mottled or banded in varying shades of brown, white and/or black) and specially adapted pelvic fins (Kuiter 1996). In particular, cocos frillgobies have developed a fused circular pelvic fin, which acts as a suction-cup allowing them to cling firmly to hard substrate base of rock pools to avoid being washed away by turbulent waves. Ringscale triplefin and eastern jumping blenny have developed smaller pelvic fins that are placed far forward on the body before the pectoral fins, which aids in lifting up the head whilst the fish is at rest (Grove and Lavenberg 1997). These three resident species also exhibit cryptic behaviours, hiding in crevices, amongst algae and under rocks, and individuals are normally observed alone or in pairs (Griffiths 2003a). All residents are bottom dwellers that feed on small invertebrates. A mixture of juveniles, sub-adults and adult residents were sighted in rock pools in this study ranging in size from 0.9-6 $\mathrm{cm}$ for cocos frillgoby, for $1-5.2 \mathrm{~cm}$ ringscale triplefin, and for $1.2-12.2 \mathrm{~cm}$ eastern jumping blenny $1.2-12.2 \mathrm{~cm}$.

Secondary residents, on the other hand, spend only a part of their life history in the intertidal zone, juveniles are usually found in rock pools, whereas sub-adults shift to off-shore habitats to complete the life history, and generally have few specialised adaptations for intertidal life (Griffiths 2003a). They grow much larger, max length recorded for fortescue $14 \mathrm{~cm}$ and stripey $16 \mathrm{~cm}$, with deep, compressed bodies and bright colouring particularly in the case of stripey with its distinct pattern of slanting black and yellow to white stripes (Kuiter 1996). The fortescue has ridges on the head and venomous spines on the dorsal, anal and pelvic fins. Secondary residents tend to be more social than residents, forming schools or small congregations. Juveniles have been reported feeding on invertebrates and algae, whilst adults prefer larger prey (Kuiter 1996). Only juveniles were sighted in rock pools during this study ranging in size from $1.3-7 \mathrm{~cm}$ for fortescue, and $1.3-7.3 \mathrm{~cm}$ for stripey.

\section{Study sites}

Studies were conducted on fish collected at a number of rock platforms in Sydney, New South Wales (Dee Why beach, Harbord Headland, Rocky Point at Balmoral Beach and Georges Head) between June 2010 and April 2012. These rock platforms were chosen for their abundance of rock pools and their relative ease of access. A total of 27 permanent tide pools were sampled at the four study sites, ranging in volume from 100 to $2,000 \mathrm{~L}$ and substrate type from sand to cobbles. We chose these pools because they were small enough to be sampled in their entirety in one day (i.e. $<10 \mathrm{~m}^{2}$ ), large enough to contain resident fish and existed within a tidal range that could be sampled during most low tides. A total of 798 fish were captured and tagged during the experiment.

\section{Experiment 1: 'Home' pool site fidelity}

To test whether intertidal fish consistently returned to a particular 'home' tide pool at low tide, we captured a total of 97 fish (ca 16 fish of each species) at low tide using small hand held nets. Fish were identified then lightly anesthetised using a solution of $50 \mathrm{mg} / \mathrm{L}$ MS222 buffered with sodium bicarbonate (fish placed in a bucket containing $1.5 \mathrm{~L}$ solution until subdued), their total length was measured and they were marked using Visible Implant Fluorescent Elastomer tags (VIE: Marine Technology, Inc. 2010). Four colours of VIE tags (red, orange, yellow or blue) were implanted beneath transparent scales in a combination of six sites along the fish's dorsal surface so they were visible to an overhead observer. This entire procedure took roughly $2 \mathrm{~min}$. After tagging, we allowed fish to recover in a bucket of fresh seawater before releasing them back into their home tide pools. Each rock pool was checked for the presence of tagged fish on days 1-7, 14 and 42 post tagging. Other nearby pools were also checked for fish that had strayed from the original pool during these days. Site fidelity was calculated as the percentage of fish found in the pool of capture for each experimental day (with the assumption that all fish captured in the original pool were not actually strays from another home pool). A repeated measures 
ANOVA was used to test for effect of time and to compare differences between fish species and residency status (StatView version 5_0_1, SAS Institute Inc. 1998).

\section{Experiment 2: Effect of displacement on homing success}

We investigated the ability of fish to return to their home pools by capturing and tagging all fish within selected rock pools at low tide and randomly displacing them to new rock pools at various distances (5, $10,15,20$ or $30 \mathrm{~m}$ ) in either direction from their original 'home' rock pool. Displacement direction was somewhat governed by availability of suitable host pools. Where possible we ensured that fish were distributed equally in each direction to different pools at each subsequent displacement distance. Fish were determined to have the ability to home if they were recaptured in their original 'home' rock pools at low tide one week after each displacement occurred. We conducted further checks of home pools one month after displacement to ensure no late returning fish were missed. Under-sampling undoubtedly occurred in some study pools as it was sometimes impossible to move/remove large boulders, and some fish wedged themselves into crevasses and could not be removed. Despite thorough checks in other pools for strays, it is possible that some fish returned but were not sampled. A generalised linear model (binomial distribution) was used to test for the effect of displacement distance, species identity, fish length and capture location on probability of returning to the home pool (SPSS statistics version 20, IBM Corp. 2011).

To improve estimates of fish site fidelity and homing success, we tested the effects of tag loss and tagging induced mortality under controlled conditions in the laboratory and found it to be 100 and $0 \%$, respectively (See supplementary material for further details).

\section{Ethical notes}

Experimental methods in this study conformed to the standards set by Macquarie University Animal Ethics committee (ARA\# 2009/021-4). Fish collections were conducted under NSW fisheries Scientific Collection Permit number P08/0010-3.0.

\section{Results}

\section{Experiment 1: Site fidelity}

Of the fish tagged in site fidelity experiment, $89 \%$ were resighted at least once during the experimental period. The percentage of fish re-sighted for individual species ranged from 33 to $76 \%$ (Table 1a). We found significant differences between residents and secondary residents in their site fidelity scores $\left(F_{1,95}=\right.$ 6.236, $P<0.001)$. The three resident species showed highest site fidelity as predicted. Of these, cocos frillgobies were most site faithful, followed by ringscale triplefins and eastern jumping blennies (Fig. 1). In contrast, secondary residents, fortescue and stripey, showed lower site fidelity compared to residents (Fisher's PLSD: $\mathrm{P} \leq 0.05$ in all cases). With the exception of secondary resident stripey, most fish were still found in the same rock pool 6 weeks after tagging occurred (Fig. 1). Overall, there was no significant interaction between residency status/life history and the passage of time on site fidelity $\left(F_{8,760}=0.943, \mathrm{P}\right.$ $>0.5$ ); however, site fidelity was species dependent. The secondary resident stripey showed a rapid decline in fidelity over time $\left(F_{8,72}=2.359, P=0.026\right)$ and were not encountered at all by the end of the 6week study. Fish that displayed strong site fidelity appeared to have their own small territory within home rock pools where they were invariably found for the duration of the study. At least $93 \%$ of re-sighted fish were observed in their original pool of capture and $7 \%$ were seen in adjacent rock pools. Only Cocos frillgobies and eastern jumping blennies had strayed to adjacent rock pools (Table 1a). 
Table 1 Tagging, recapture and homing success data for fish species used in (a) site fidelity and (b) displacement experiments

\begin{tabular}{|c|c|c|c|c|c|}
\hline \multirow[t]{2}{*}{ Species } & \multicolumn{3}{|c|}{ (a) Site fidelity } & \multicolumn{2}{|c|}{ (b) Displacement } \\
\hline & $\begin{array}{l}\text { No. of } \\
\text { fish } \\
\text { tagged }\end{array}$ & $\begin{array}{l}\text { Average } \\
\text { return } \\
\text { rate }(\%)\end{array}$ & $\begin{array}{c}\% \text { Fish } \\
\text { found in } \\
\text { adjacent } \\
\text { pools }\end{array}$ & $\begin{array}{l}\text { No. of } \\
\text { fish } \\
\text { tagged }\end{array}$ & $\begin{array}{c}\text { Homing } \\
\text { success } \\
(\%)\end{array}$ \\
\hline $\begin{array}{l}\text { Bathygobius } \\
\text { cocosensis } \\
\text { (resident) }\end{array}$ & 37 & 77 & 14 & 145 & 60 \\
\hline $\begin{array}{l}\text { Enneapterygius } \\
\text { atrogulare } \\
\text { (resident) }\end{array}$ & 18 & 65 & 0 & 62 & 58 \\
\hline $\begin{array}{l}\text { Lepidoblennius } \\
\text { haplodactylus } \\
\text { (resident) }\end{array}$ & 16 & 77 & 6 & 62 & 48 \\
\hline $\begin{array}{l}\text { Centropogon } \\
\text { australis } \\
\text { (secondary } \\
\text { resident) }\end{array}$ & 16 & 69 & 0 & 61 & 20 \\
\hline $\begin{array}{l}\text { Microcanthus } \\
\text { strigatus } \\
\text { (secondary } \\
\text { resident) }\end{array}$ & 10 & 34 & 0 & 30 & 3 \\
\hline Total & 97 & 65 & 7 & 360 & 41 \\
\hline
\end{tabular}

'Adjacent' rock pools are $<5 \mathrm{~m}$ from original rock pool of capture

\section{Experiment 2: Homing success}

The percentage of fish returning to home tide pools after displacement varied significantly between residents and secondary residents (Wald Chi Square, $X_{\frac{2}{2}}^{2}=21.856, P<0.001$ ) and ranged from 7 to $62 \%$ between species. As predicted, the three resident species obtained highest return rates after displacement. Of these, cocos frillgobies were most likely to return, followed by ringscale triplefins and then eastern jumping blennies (Fig. 1). Much like the results of site fidelity experiment, secondary residents fortescue and stripey were least likely to home to their original pool of capture. The return rate for secondary resident stripey was significantly lower than all other fish species $(P<0.001$ in all cases), with only five out of 62 individuals recaptured (Table $1 \mathrm{~b}$ ).

Overall, homing success was not affected by displacement distance for residents or secondary residents (Wald Chi Square, $X_{\frac{2}{2}}^{2}=6.848, P=0.232$ ). Closer inspection of the data the species level using regression analyses revealed that displacement distance was related to the probability of returning home in two species. Cocos frillgoby showed significantly less tendency to home as displacement distance increased $\left(F_{1,224}=5.661, \mathrm{P}=0.018\right)$, but this result only explained $2 \%$ of variability in homing success experienced by this species. Eastern jumping blenny also showed significantly less tendency to home as displacement distance increased $\left(F_{1,110}=7.593, P=0.007\right)$. All species continued to return even after being displaced $30 \mathrm{~m}$ (Fig. 2), except for stripey which did not home at all.

Fish length was found to have a significant effect on homing ability for secondary residents (Wald Chi square, $X_{\frac{2}{2}}^{2}=7.755, P=0.005$ ) but not resident species (Wald Chi square, $X_{\frac{2}{2}}^{2}=0.382, P=0.537$ ). Further analyses at the species level revealed that homing ability remained relatively similar regardless of size for 
all species except one (Fig. 3). The secondary resident fortescue showed significantly greater tendency to home as they increased in size, once they reach an intermediate size, however, homing skills appear to become less accurate and decline as size increased (Wald Chi Square, $X_{\frac{2}{2}}^{2}=7.706, P=0.006$ ) (Fig. 3d). In this species, body size explained $15 \%$ of the variability in homing success.

Location where fish were caught had a significant effect on homing success (Wald Chi square, $X_{\frac{2}{2}}^{2}=$ 15.183, $P=0.002$ ), fish caught at Balmoral Beach were less likely to home than those caught at Chowder Bay. There was also significant length by location interaction (Wald Chi square, $X_{\frac{2}{2}}^{2}=10.516, P=0.015$ ). Although there were small differences in homing ability for resident and secondary resident species that appeared to be associated with study site location, none showed significant differences between capture locations in their own right $(P>0.1$ in all cases).

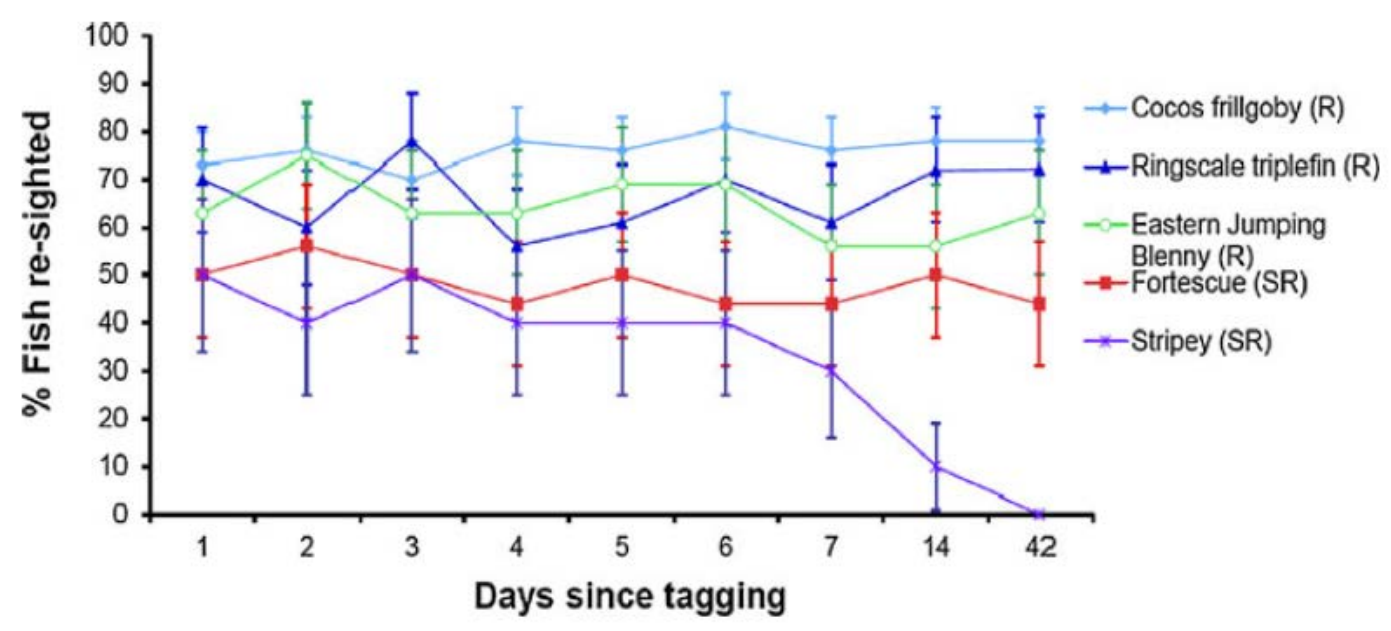

Fig. 1 Mean $( \pm S E)$ percentages of fish re-sighted in original rock pools during the 42-day period of the control treatment. Species denoted with an asterisk are residents, those without are secondary residents

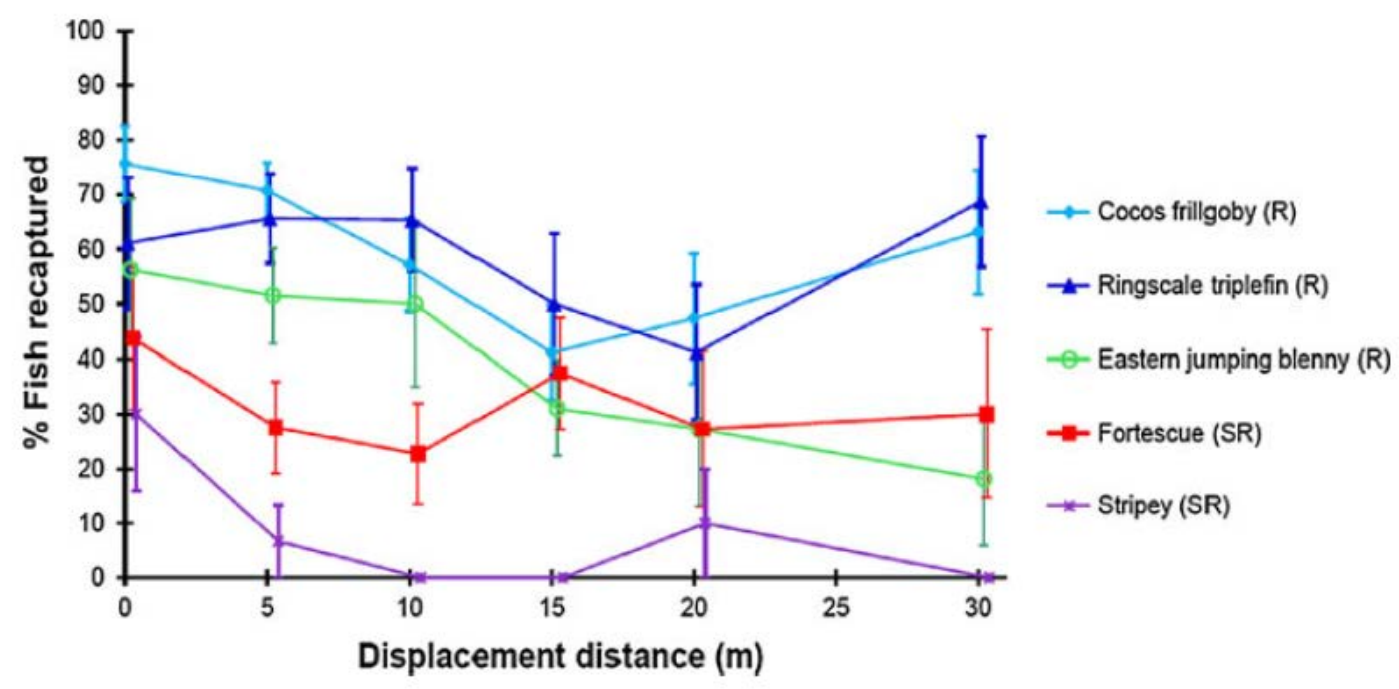

Fig. 2 Mean $( \pm S E)$ percentages of fish homing to original rock pools after being displaced at distances of 0,5 , 10, 15, 20 and $30 \mathrm{~m}$. Species denoted with an asterisk are residents, those without are secondary residents 


\section{Discussion}

Our study indicates that intertidal rock pool fishes display long-term site fidelity and are capable of homing over distances exceeding $30 \mathrm{~m}$. However, the extent to which individuals remain faithful to their home pools is dependent on their residency status. Resident intertidal species displayed much stronger site fidelity than did secondary resident species. Homing success for residents was also much greater than that of secondary residents, providing support for the ecological cognition hypothesis. Despite expectations to the contrary, homing success was stable across all displacement distances. These findings emphasise the importance of site familiarity to intertidal fishes, indicating that the ability to home to a familiar site has beneficial impacts on an individual's fitness. Furthermore, this study provides support to numerous other studies where animals show prolonged site fidelity to a single area (molluscs, Stimson 1970; mammals, Komers 1996; amphibians, Welsh and Droege 2001) or complete costly journeys in order to home to familiar places (reptiles, Limpus et al. 1992; birds, Part 1995; insects, Conradt et al. 2001).

Our results show that sight fidelity varied significantly between species, but more specifically, that some intertidal species (residents) have a stronger tendency to occupy a single home rock pool than others (secondary residents) (Fig. 3). There are a number of factors that may contribute to these differences. Firstly, rock pool selection criteria in secondary residents change during ontogeny. Opaleye, for example, migrate to lower level rock pools as they grow which is associated with shifts in diet and habitat preferences (Valle 1989). This accounts for the poor site fidelity results obtained by secondary residents in the present study as both these species have been reported to enter the intertidal zone as larvae/ juveniles and then leave for offshore habitats once they have reached adulthood or conditions become unsuitable (Kuiter 1996; Gommon et al. 2008; McGrouther 2012). The three resident species are known to be tide-pool specialists, and thus, most of them remained in their home pools throughout the six-week study period. Secondly, an individual's home range may be dynamic and vary over time and space according to the physical characteristics of the pool (Green 1971; Griffiths 2003b). For example, pools lower in the tidal range may be preferred during warmer periods when increased salinity and water temperatures and decreased oxygen makes pools higher up on the rock platform uninhabitable. Each species may vary in the level of tolerance to these physical water parameters and therefore vary in the extent to which they remain faithful to their home pool. We currently lack sufficient information on present study species with respect to their habitat requirements and physiological tolerances.

Overall, homing success was not greatly affected by displacement distance, suggesting that distances at which these fish were released were well within their home ranges or the cues available for homing were still salient at $30 \mathrm{~m}$. Likewise, Griffiths (2003b) found that there were no differences in proportion of fish recaptured when released at distances of $<20 \mathrm{~m}$. Stripey and fortescue displayed the poorest homing ability, which is not surprising, considering their poor site fidelity, secondary resident status and life history strategy, presumably they may have chosen to shift offshore rather than failing to home (Table 1). In fact, only five individual stripey returned to pool of capture after displacement and it is possible that these individuals may have ended up in their 'home' pool purely by chance. Strong homing abilities observed in the three resident species, cocos frillgoby, ringscale triplefin and eastern jumping blenny, strongly suggest that evolution has favoured the development of a keen spatial learning ability (Fig. 3). Resident cocos frillgoby was the only species to show a significant effect of displacement distance on probability of returning home but the relationship was not linear and their homing success remained high even after begin displaced $30 \mathrm{~m}$. Clearly, we need to extend the displacement distance further in these resident species in future studies. 


\section{Residents}

(a) Cocosfrillgoby

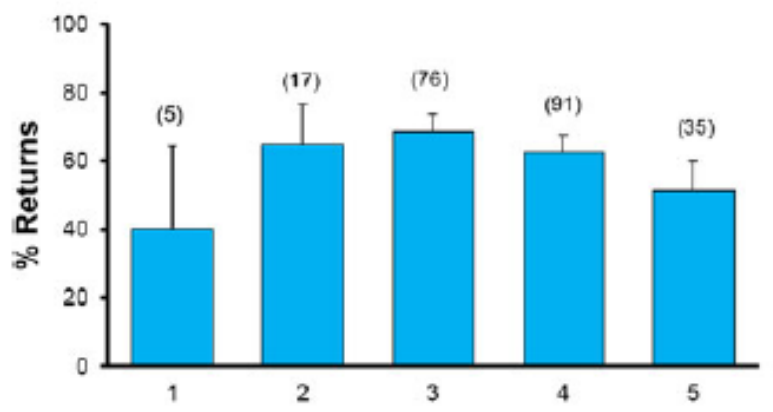

(b) Ringscale triplefin

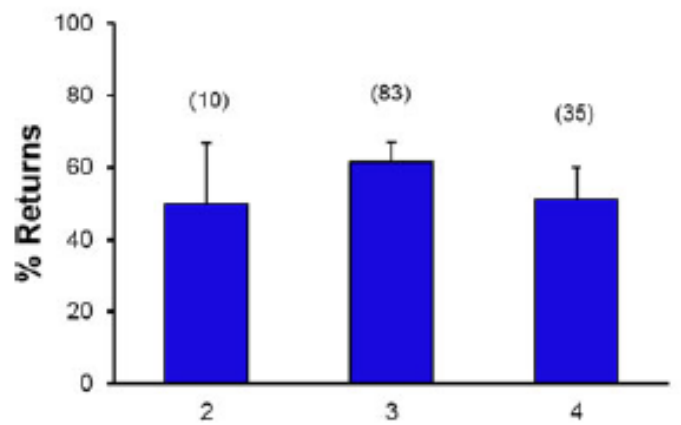

(c) Eastern jumping blenny

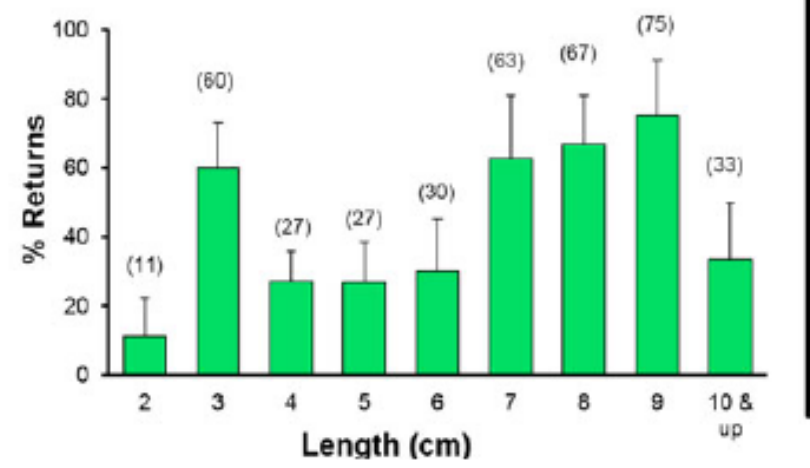

\section{$\underline{\text { Secondary Residents }}$}

(d) Fortescue

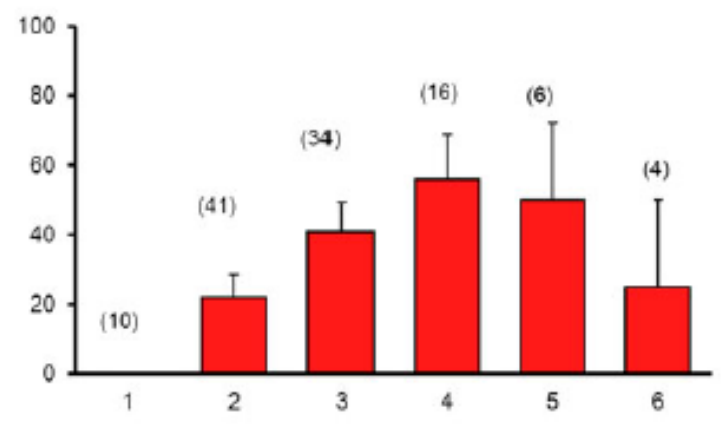

(e) Stripey

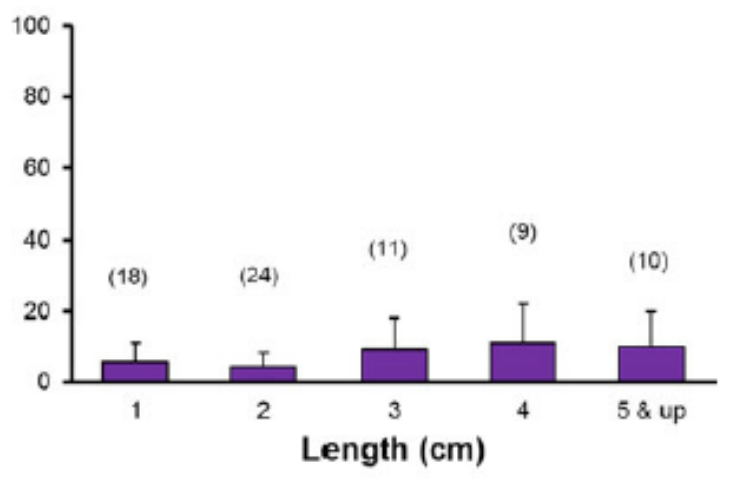

Fig. 3 Mean $( \pm S E)$ percentages of fish returning as a function on body size (length in $\mathrm{cm}$ ) for the three resident species [a] cocos frillgoby, [b] ringscale triplefin and [c] eastern jumping blenny, and the two secondary resident species [d] fortescue and [e] stripey. Number in brackets above each column is the number of fish tested of this size

When trying to return home, it is likely that displaced fish explore the new area until they discover some familiar landmark or some other cue (perhaps chemosensory) that is useful in orientation over long distances (Odling-Smee and Braithwaite 2003). It is hard to imagine how salient chemosensory cues 
would be given turbulence experienced in the intertidal zone but intertidal species have a range of cues available to them including polarised light, wave and tide direction. We expect that once the fish approach home, however, they use spatial memories of the local topography acquired whilst swimming over surrounding area at high tide to relocate their home pools (Aronson 1951, 1971). Those individuals that were not recaptured in original pools may have been displaced to a distance well beyond the areas they have explored during high tide excursions, although it is well documented that animals are capable of returning home from distances beyond their home range (e.g. Hammilton 1937).

Failure of some resident fish to return to their original pool of capture in this study may be explained by settlement in a new pool following failure to relocate the home pool. When fish is displaced to an unfamiliar location, they face the threat of predation or becoming stranded if they do not locate a suitable rock pool quickly. Thus, it is in their best interest to trade off the risk involved in searching for their original home pool against those of adopting a new home pool in the immediate vicinity. At most release sites, suitable rock pools were available close by, including release pools themselves. As long as suitable resources are available in unfamiliar rock pools, then settlement can occur in normally site-attached individuals (Armstrong et al. 1997; Belanger and Rodriguez 2001). Since we relocated fish at low tide, they had some time to become familiar with their new pool before the tide came in. It has been reported in salmonids that straying from natal spawning sites allows for colonisation of new habitats and avoidance of areas in which local conditions have become unfavourable (Milner 1987; Milner and Bailey 1989), this theory may also prove true for intertidal fish species. It is possible that some fish caught in the original pool may have been strays and thus were not capable of homing to this pool because it was not actually their home pool. Whilst we lacked the capacity to repeatedly survey every rock pool on the rock platform at all sites, such an approach would be informative as to fate of non-returns. Nevertheless, probability of fish returning to their home range having been displaced at various distances may provide some insight into the size of the area these fish explore at high tide or salience of required homing cues over these distances.

We found that body size had some influence upon homing success for one of the species tested but not on the other four species. The secondary resident fortescue showed a significantly greater tendency to home as it increases in size, once it reaches an intermediate size, however, homing skills appear to become less accurate. This suggests that individuals in this species become increasingly familiar with the layout of the rock platform in their early life history when homing is more important to their survival, and then, once they reach a certain threshold size, they cease to home rather suddenly at time of dispersal to offshore habitats. Only individuals of a small to medium size were tested for homing ability in the present study, as larger mature fortescue have already left the rock platform in favour of seagrass beds in coastal bays. It would be valuable to capture these larger fish and test their spatial memory once they have left the rock platform. One would predict that their spatial memory would decline significantly once they have dispersed. It is clear that further experiments need to be conducted to examine physical verses psychological developmental aspects of homing behaviour in these species.

To conclude, there are clear differences in site fidelity and homing skills of intertidal fish species that are related to life history traits as predicted by the ecological cognition hypothesis. It seems clear that natural selection does favour evolution of enhanced spatial memories in rock pool resident species. By comparison, the level of selective pressure is significantly less on secondary residents once they reach a threshold size and shift to offshore habitats and thus homing skills deteriorate. What remains unclear, however, is what cues these fish use to return to their home pool. One can speculate that they likely utilise a range of cues and that these may vary with distances from the home pool. We currently lack knowledge about movements of these fish at high tide because it is difficult to follow them in real time in 
the turbulent intertidal zone, but these displacement studies clearly indicate that their knowledge of the environment extends well beyond their home pool.

\section{Acknowledgments}

Many thanks are due to Anthony C. Gill for help with fish identification, Emilie Theurant, Maxime Lalire and Gary White for assistance with fieldwork, Martin Whiting and anonymous reviewers for comments on manuscript and Macquarie University for providing the funds necessary to perform this study.

\section{References}

Armstrong JD, Braithwaite VA, Huntingford FA (1997) Spatial strategies of wild Atlantic salmon parr: exploration and settlement in unfamiliar areas. J Anim Ecol 66:203-211

Aronson LR (1951) Orientation and jumping behaviour in the gobiid fish Bathygobius soporator. Amer Mus Nov 1486:1-12

Aronson LR (1971) Further studies of the orientation and jumping behaviour in the gobiid fish Bathygobius soporator. Ann NY Acad Sci 188:378-407

Balda RP, Kamil AC (1992) Long-term spatial memory in Clark's nutcracker, Nucifraga Columbiana. Anim Behav 44:761-769

BeebeW(1931)Notes on the frill-finned goby. Zoologica (NY) 12:55-66

Belanger G, Rodriguez MA (2001) Homing behaviour of stream dwelling brook charr following experimental displacement. J Fish Biol 59:987-1001

Berti R, Colombini I, Chelazzi L, Ercolini A (1994) Directional orientation in Kenyan populations of Periophthalmus sobrinus Eggert: experimental analysis of the operating mechanisms. J Exp Mar Biol Ecol 18:135-141

Brown C (2001) Familiarity with the test environments improves escape responses in the crimson spotted rainbow fish Melanotaenia duboulayi. Anim Cog 4(2):109-113

Brown C, Braithwaite VA (2004) Effects of predation pressure on the cognitive ability of the poeciliid Brachyraphis episcopi. Behav Ecol 16:482-487

Carlson HR, Haight RE (1972) Evidence for a home site \& homing of adult Yellowtail Rockfish, Sebastes flavidus. J Fish Res Board Can 29:1011-1014

Conradt L, Roper TJ, Thomas CD (2001) Dispersal behaviour of individuals in metapopulations of two British butterflies. Oikos 95:416-424

Costa SS, Andrade R, Carneiro LA, Gonçalves EJ, Kotrschal K, Oliveira RF (2011) Sex differences in the dorsolateral telencephalon correlate with home range size in blenniid fish. Brain Behav Evol 77:55-64

Gaulin SJC, Fitzgerald RW (1986) Sex differences in spatial ability: on evolutionary hypothesis and test. Am Nat 127:74-88

Gerking SD (1959) The restricted movement of fish populations. Biol Rev 34:221-242

Gibson RN (1999) Movement and homing in intertidal fishes. In: Horn MH, Martina KLM, Chotkowski MA (eds) Intertidal fishes, life in two worlds. Academic Press, USA, pp 97-125

Gommon MF, Bray DJ, Kuiter RH (2008) Fishes of Australia's Southern Coast. New Holland

Green JM (1971) High tide movements and homing behaviour of the tide pool sculpin Oligacattus macullasus. J Fish Res Board Can 28:383-389

Griffiths SP (2003a) Rockpool ichthyofaunas of temperate Australia: species composition, residency and biogeographic patterns. Estuar Coast Shelf Sci 58:173-186 
Griffiths SP (2003b) Homing behaviour of intertidal rock pool fishes in South-Eastern New South Wales, Australia. Aust J Zool 51:387-398

Grove JS, Lavenberg RJ (1997) The fishes of the Galápagos Islands. Standford University Press, California, $\mathrm{p} 513$

Hammilton WJ Jr (1937) Activity and home range of the field mouse, Microtus p. pennsylvanicus (Ord.). Ecology 18:255-263

Healy S (1998) Spatial representation in animals. Oxford University Press, Oxford

Healy S, Braithwaite V (2000) Cognitive ecology: a field of substance? Trends Ecol Evol 15:22-26

Khoo HW (1974) Sensory basis of homing in intertidal fish Oligocottus maculosus Girard. Can J Zool 52:1023-1029

Kolm N, Hoffman EA, Olsson J, Berglund A, Jones AG (2005) Group stability and homing behavior but no kin group structures in a coral reef fish. Behav Ecol 16:521-527

Komers PE (1996) Obligate monogamy without paternal care in Kirk's dikdik. Anim Behav 51:131-140

Kuiter RH (1996) Guide to sea fishes of Australia. New Holland.pp 433

Letty J, Aubineau J, Marchandeau S, Clobert J (2003) Effect of translocation on survival in wild rabbit (Oryctlagus cuniculus). Mamm Biol 68:250-255

Limpus CJ, Miller JD, Parmenter CJ, Reimer D, Mclachlan N, Webb R (1992) Migration of green (Chelonia mydas) and loggerhead (Caretta caretta) turtles to and from eastern Australian rookeries. Wildl Res 19:347-358

Marine Technology, Inc. (2010) VIE manual injection kits. Northwest Marine Technology, Inc. http://www.nmt.us/products/vie/vie.shtml. Accessed 22 June 2012

Maynard Smith J, Parker GA (1976) The logic of asymmetric contests. Anim Behav 24(159):175

McGrouther M (2012) Fishes of Sydney Harbour. Australian Museum. http://australianmuseum.net.au/Fishes-of-Sydney-Harbour. Accessed 22 June 2012

Milner AM (1987) Colonization and ecological development of new streams in Glacier Bay National Park Alaska. Freshw Biol 18:53-70

Milner AM, Bailey RG (1989) Salmonid colonization of new streams in Glacier Bay National Park Alaska. Aquac Fish Manage 20:179-192

Odling-Smee L, Braithwaite VA (2003) The influence of habitat stability on landmark use during spatial learning in the three-spined stickleback. Anim Behav 65:701-707

Papi F (1992) General aspects. In: Papi F (ed) Animal homing. Chapman and Hall, London, pp 1-18

Part T (1995) The importance of local familiarity and search costs for age-biased and sex-biased philopatry in the collared flycatcher. Anim Behav 49:1029-1038

Piper WH (2011) Making habitat selection more familiar: a review. Behav Ecol Sociobiol 65:1329-1351

Reinert HK, Rupert RRJ (1999) Impacts of translocation on behavior and survival of timber rattlesnakes, Crotalus horridus. J Herpetol 33:45-61

Stephens JS, Johnson RK Jr, Key GS, McCosker JE (1970) The comparative ecology of three sympatric species of California blennies of the genus Hypsoblennius Gill (Teleostomi, Blennidae). Ecol Monogr 40:213-233

Stimson J (1970) Terrritorial behavior of the owl limpet, Lottia gigantea. Am Nat 157:154-169

Valle CF (1989) Homing behaviour and intertidal movement of the opaleye, Girella nigricans, (Pisces: Kyphosidae). Marine Science thesis, California State University, California

Welsh HH, Droege S (2001) A case for using plethodontid salamanders for monitoring biodiversity and ecosystem integrity of North American forests. Conserv Biol 15:558-569

Williams GC (1957) Homing behaviour of California rocky shore fishes. Univ Calif Publ Zool 59:249-284

Yoshiyama RM, Gaylord KB, Philippart MT, Moore TR, Jordan JR, Coon CC, Schalk LL, Valpey CJ, Tosques I (1992) Homing behaviour and site fidelity in intertidal sculpins (Pisces: Cottidae). J Exp Mar Biol Ecol 160:115-130 